\title{
Mo-doped boron nitride monolayer as a promising single-atom electrocatalyst for $\mathrm{CO}_{2}$ conversion
}

\author{
Qianyi Cuii ${ }^{1}$, Gangqiang Qin ${ }^{1}$, Weihua Wang ${ }^{2}$, Lixiang Sun ${ }^{3}$, Aijun Du $^{4}$ and Qiao Sun ${ }^{* 1}$
}

\author{
Full Research Paper \\ Address: \\ ${ }^{1}$ State Key Laboratory of Radiation Medicine and Protection, \\ Collaborative Innovation Center of Radiation Medicine of Jiangsu \\ Higher Education Institutions, School for Radiological and \\ Interdisciplinary Sciences, Soochow University, Suzhou 215123, \\ China, ${ }^{2}$ School of Chemistry and Chemical Engineering, Qufu Normal \\ University, Qufu, Shandong, 273165, China, ${ }^{3}$ College of Chemistry \\ and Materials Science, Ludong University, Yantai 264025, China and \\ ${ }^{4}$ School of Chemistry, Physics and Mechanical Engineering, \\ Queensland University of Technology, Brisbane, QLD 4001, Australia \\ Email: \\ Qiao Sun* - sunqiao@suda.edu.cn \\ * Corresponding author \\ Keywords: \\ boron nitride monolayer; $\mathrm{CO}_{2}$ conversion; density functional theory; \\ single-atom electrocatalyst \\ Beilstein J. Nanotechnol. 2019, 10, 540-548. \\ doi:10.3762/bjnano. 10.55 \\ Received: 24 August 2018 \\ Accepted: 01 February 2019 \\ Published: 22 February 2019 \\ Associate Editor: J. Frommer \\ (c) 2019 Cui et al.; licensee Beilstein-Institut. \\ License and terms: see end of document.
}

\begin{abstract}
The design of new, efficient catalysts for the conversion of $\mathrm{CO}_{2}$ to useful fuels under mild conditions is urgent in order to reduce greenhouse gas emissions and alleviate the energy crisis. In this work, a series of transition metals (TMs), including Sc to Zn, Mo, $\mathrm{Ru}, \mathrm{Rh}, \mathrm{Pd}$ and $\mathrm{Ag}$, supported on a boron nitride (BN) monolayer with boron vacancies, were investigated as electrocatalysts for the $\mathrm{CO}_{2}$ reduction reaction (CRR) using comprehensive density functional theory (DFT) calculations. The results demonstrate that a single-Mo-atom-doped boron nitride (Mo-doped $\mathrm{BN}$ ) monolayer possesses excellent performance for converting $\mathrm{CO}_{2}$ to $\mathrm{CH}_{4}$ with a relatively low limiting potential of $-0.45 \mathrm{~V}$, which is lower than most catalysts for the selective production of $\mathrm{CH}_{4}$ as found in both theoretical and experimental studies. In addition, the formation of OCHO on the Mo-doped BN monolayer in the early hydrogenation steps is found to be spontaneous, which is distinct from the conventional catalysts. Mo, as a non-noble element, presents excellent catalytic performance with coordination to the BN monolayer, and is thus a promising transition metal for catalyzing CRR. This work not only provides insight into the mechanism of CRR on the single-atom catalyst (Mo-doped BN monolayer) at the atomic level, but also offers guidance in the search for appropriate earth-abundant TMs as electrochemical catalysts for the efficient conversion of $\mathrm{CO}_{2}$ to useful fuels under ambient conditions.
\end{abstract}

\section{Introduction}

In the past decades, considerable carbon dioxide emissions into the atmosphere due to large-scale anthropogenic industrial manufacturing have resulted in global climate change effects
[1]. Thus, it is very important to develop advanced technologies for efficient $\mathrm{CO}_{2}$ capture, storage and conversion [2]. Carbon dioxide storage technologies have made great progress in 
recent years [3-5], which provides a feasible foundation for converting $\mathrm{CO}_{2}$ into useful fuel and commodity chemicals [6]. For example, $\mathrm{CO}_{2}$ can be converted to methane, methanol and formic acid, and all of which can be used as energy sources and chemical materials at the global scale [7-11]. In this sense, the $\mathrm{CO}_{2}$ reduction reaction (CRR) by electrochemical methods is promising because it can take place at room temperature and atmospheric pressure with useful catalysts, making it feasible for extensive application and integration [12-14].

Metal nanoparticles supported on various substrates have been extensively investigated as heterogeneous catalysts in many reactions [10,15-17]. Over the past few decades, researchers have focused on decreasing the size of metal nanoparticles in order to improve the surface area/volume ratio of low-coordinated metal atoms in order to enhance the selectivity toward specific species and to improve the electrocatalytic performance [18-20]. The ultimate size limit for metal particles is single-atom catalysts (SACs), in which the isolated single metal atoms distribute on the substrates in an ordered fashion [21]. Moreover, the single metal atoms are supported on the substrates as active sites, which exhibit higher catalytic efficiency than conventional nanoparticles [22-25]. To date, the catalysts that have employed various single transition metal (TM) atoms anchored on the different substrates such as graphene [26-29] and graphitic carbon nitride [30-34], have presented good performance and high efficiency.

As an analogue of graphene, boron nitride (BN) nanomaterials have sparked worldwide interest in exploring their applications in many fields, both experimentally and theoretically, due to their excellent properties, such as high chemical stability, thermal conductivity, oxidation resistance and refractory nature [11,35-41]. Moreover, BN nanomaterials have been used as superior substrates for doping various transition metals by electron beam irradiation [42] or solvent exfoliation [43] to form selected point defects, which are preferred to growing specific boron vacancies $[42,44]$. Recent reports show that single-TMdoped $\mathrm{BN}$ nanomaterials have been used as efficient catalysts in the reactions of $\mathrm{N}_{2}$ fixation and $\mathrm{CO}$ oxidation $[45,46]$. It is worth noting that Chen and co-workers reported that single Mo supported on defective BN nanosheets presents a highly efficient electrocatalyst for nitrogen fixation with a very small overpotential of only $0.19 \mathrm{~V}$. In addition, through molecular dynamics modeling, they demonstrated that Mo-doped BN synthesized in acidic conditions is stable at high temperature $(500 \mathrm{~K})$ [45]. In our previous reports, we have studied $\mathrm{BN}$ nanomaterials used as efficient materials for $\mathrm{CO}_{2}$ capture and gas separation [35,47]. The excellent performance of $\mathrm{BN}$ nanomaterials in various applications have inspired us to study whether the materials can be efficient catalysts for $\mathrm{CO}_{2}$ reduction. To answer this question, we have screened possible SACs involving fifteen $\mathrm{TMs}(\mathrm{TM}=\mathrm{Sc}$ to $\mathrm{Zn}, \mathrm{Mo}, \mathrm{Rh}, \mathrm{Ru}, \mathrm{Pd}$ and $\mathrm{Ag})$ anchored on the boron vacancy in a $\mathrm{BN}$ monolayer as electrocatalysts for $\mathrm{CO}_{2}$ conversion through comprehensive density functional theory (DFT) calculations. Based on the calculated results, single Mo doped onto a BN (Mo-doped BN) monolayer was selected as the catalyst for further investigation of $\mathrm{CO}_{2}$ conversion due to its high selectivity and activation for $\mathrm{CO}_{2}$. The study shows that Mo-doped BN monolayers can be used as a promising catalyst for $\mathrm{CO}_{2}$ reduction to $\mathrm{CH}_{4}$ with a low limiting potential of $-0.45 \mathrm{~V}$. More importantly, Mo is an abundant element in the earth, thus using Mo-doped BN monolayers as an electrocatalyst for $\mathrm{CO}_{2}$ conversion can significantly reduce the cost compared with conventional noble-metal catalysts, such Au, Ag, Pt, $\mathrm{Pd}$ and so on $[30,33,48,49]$. This work provides insight and guidance to experimentalists in search of low cost, high efficiency SACs for converting $\mathrm{CO}_{2}$ to useful hydrocarbon fuels.

\section{Results and Discussion Transition metal selection for $\mathrm{CO}_{2}$ reduction reaction}

For efficient $\mathrm{CO}_{2}$ reduction, the most critical requirement is that the $\mathrm{CO}_{2}$ molecule can selectively adsorb onto the catalyst and guarantee sufficient activation for CRR $[9,11]$. This is a widely used, basic criterion for selecting catalyst materials for electrocatalysts in $\mathrm{TM}$-doped $\mathrm{BN}$ for the $\mathrm{N}_{2}$ reduction reaction, whereby the criterion is that the catalyst can facilitate the chemisorption of $\mathrm{N}_{2}$ molecules [45]. To screen for promising transition metals to be doped onto BN monolayers (TM-doped $\mathrm{BN}$ ) as the SACs, the interaction between $\mathrm{CO}_{2}$ and various TM (Sc to $\mathrm{Zn}, \mathrm{Mo}, \mathrm{Ru}, \mathrm{Rh}, \mathrm{Pd}$ and $\mathrm{Ag}$ ) doped $\mathrm{BN}$ monolayers were considered. Moreover, for efficient reduction of $\mathrm{CO}_{2}$, the interaction between $\mathrm{CO}_{2}$ and the catalyst should be stronger than that between $\mathrm{H}_{2} \mathrm{O}$ and the catalyst. Therefore, we calculated the adsorption energy $\left(\Delta E_{\text {ads }}\right)$ of $\mathrm{CO}_{2}$ and $\mathrm{H}_{2} \mathrm{O}$ on TM-doped $\mathrm{BN}$ monolayers. The $\Delta E_{\text {ads }}$ of all structures is calculated using $\Delta E_{\text {ads }}=E_{\text {gas-catal }}-E_{\text {gas }}-E_{\text {catal }}$, where $E_{\text {gas-catal }}$ represents the energy of the whole absorbed structure, and $E_{\text {gas }}$ and $E_{\text {catal }}$ represent the energy of the free gas molecule and the clean surface, respectively. The calculation results are exhibited in Figure 1 and Supporting Information File 1, Table S2, showing various properties of the most stable configurations of $\mathrm{CO}_{2}$ and $\mathrm{H}_{2} \mathrm{O}$ adsorbed on TM-doped BN (Figure 1a) and corresponding structural parameters, such as $\mathrm{C}-\mathrm{O}$ bond length (Figure 1b) and the angle (Figure 1c) of the $\mathrm{CO}_{2}$ molecule adsorbed onto the TM-doped BN. As shown in Figure 1a, there are significant differences in the $\mathrm{CO}_{2}$ adsorption on the various TM-doped $\mathrm{BN}$ monolayers, where the system with the more negative value of adsorption energy means a stronger interaction. Therefore, it can be seen clearly from Figure 1a that there is weak adsorp- 
tion between $\mathrm{CO}_{2}$ and some of the TM-doped BN monolayers, including $\mathrm{Sc}, \mathrm{Mn}, \mathrm{Fe}, \mathrm{Co}, \mathrm{Ni}, \mathrm{Zn}, \mathrm{Ru}, \mathrm{Rh}, \mathrm{Pd}$ and $\mathrm{Ag}$, whose adsorption energy values are not negative enough to satisfy the requirements as catalysts for CRR.

In contrast with Figure 1a, the geometric configuration of $\mathrm{CO}_{2}$ captured by TM-doped BN is in good agreement with the values of the adsorption energies - Figure $1 \mathrm{~b}$ reflects that the inert $\mathrm{C}-\mathrm{O}$ double bond of $\mathrm{CO}_{2}$ can be stretched by strong adsorption on some TM-doped BNs (Ti, V, Cr and Mo). On the other hand, the variation of the $\mathrm{C}-\mathrm{O}$ bond is negligible which has weak adsorption on the TMs ( $\mathrm{Sc}, \mathrm{Mn}, \mathrm{Fe}$ and so on) mentioned above (Figure 1b). In addition, it is worth noting that the $\mathrm{C}-\mathrm{O}$ bond interacts with Mo, whose tensile effect is the most significant in the series of TMs we screened. Meanwhile, the $\mathrm{CO}_{2}$ angle is also determined by the strength of the interaction of $\mathrm{CO}_{2}$ with different TMs that anchor on the BN monolayer. The configuration of captured $\mathrm{CO}_{2}$ is significantly distorted by strong chemisorption as illustrated in Figure 1a-c. Regarding the elec- tronic properties, physisorption of $\mathrm{CO}_{2}$ results in a positive charge state; however, chemisorption of $\mathrm{CO}_{2}$ results in a negative charge state, because electrons are transferred to the captured $\mathrm{CO}_{2}$ from the TM-doped $\mathrm{BN}$ monolayer (Figure 1d).

$\mathrm{CO}_{2}$ must be readily captured by the catalyst, and the interaction between $\mathrm{CO}_{2}$ and the catalyst should be stronger than that between $\mathrm{H}_{2} \mathrm{O}$ and the catalyst. From Figure 1a we can also see that, except for the Mo-doped BN monolayer, whose interaction with $\mathrm{CO}_{2}$ is stronger than that of $\mathrm{H}_{2} \mathrm{O}$, the other TM-doped BNs prefer adsorbing $\mathrm{H}_{2} \mathrm{O}$ to $\mathrm{CO}_{2}$. The most stable configurations of $\mathrm{CO}_{2}$ and $\mathrm{H}_{2} \mathrm{O}$ adsorption on the surface of the Mo-doped BN monolayer are shown in Figure $2 \mathrm{a}$ and $\mathrm{b}$, respectively. Figure 2a shows that the two chemical bonds, C-Mo and O-Mo, formed with lengths of $2.093 \AA$ and $2.092 \AA$, respectively. The angle of $\mathrm{O}-\mathrm{C}-\mathrm{O}$ is stretched from $180^{\circ}$ for the isolated $\mathrm{CO}_{2}$ to $135.7^{\circ}$ for the captured one. The $\mathrm{O}-\mathrm{C}$ bond interacted with Mo atom lengths from $1.176 \AA$ of the free $\mathrm{CO}_{2}$ molecule to $1.309 \AA$ of the adsorbed one (Supporting Information File 1,
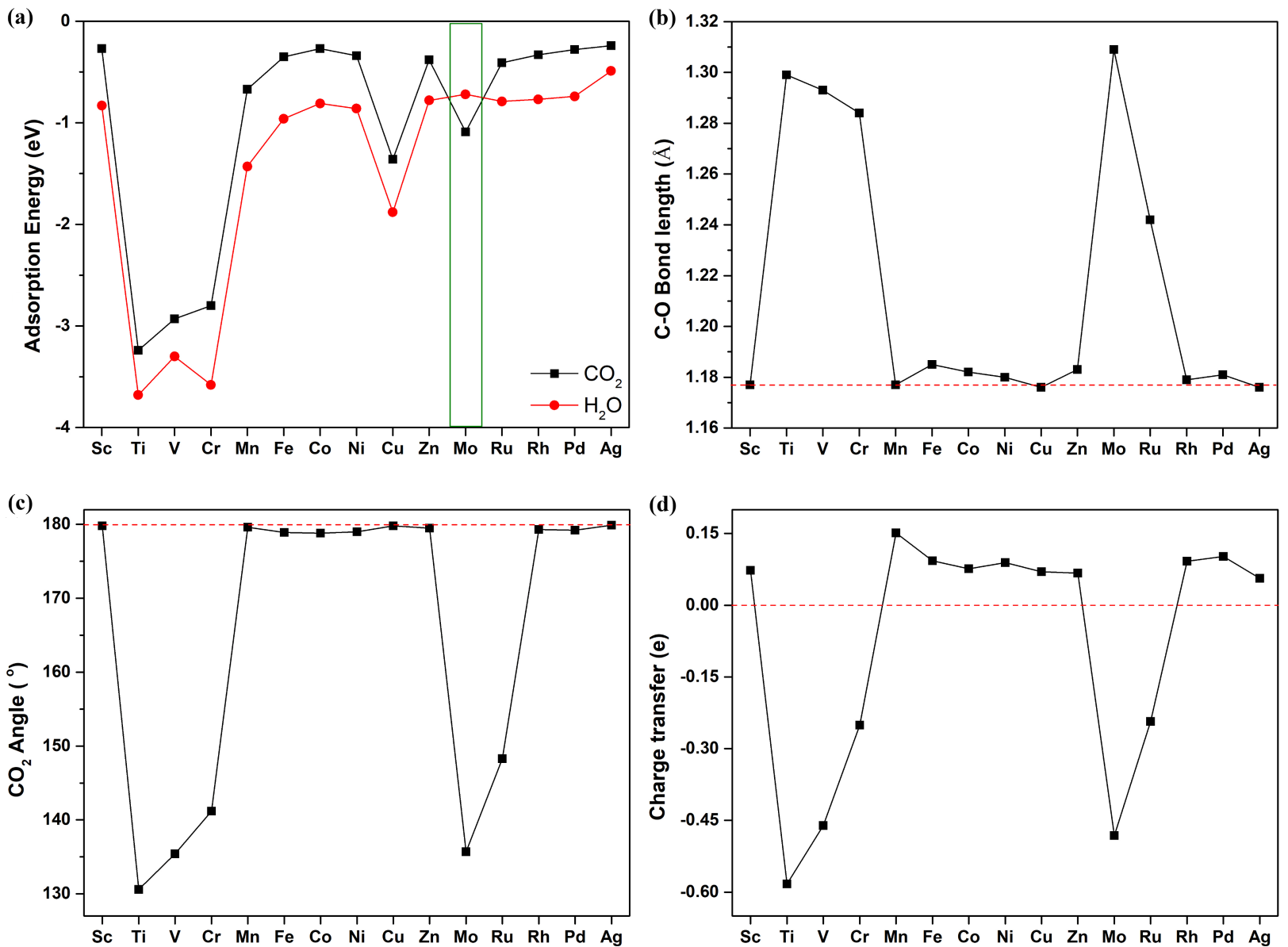

Figure 1: (a) Adsorption energy of $\mathrm{CO}_{2}$ and $\mathrm{H}_{2} \mathrm{O}$ on various single transition metal (TM) doped $\mathrm{BN}$ monolayers. (b) The length of the $\mathrm{C}-\mathrm{O}$ bond of $\mathrm{CO}_{2}$ that interacts with the TM atom doped onto the $\mathrm{BN}$ monolayers. (c) The angle of the captured $\mathrm{CO}_{2}$ molecule. (d) The charge transfer of $\mathrm{CO}_{2}$ adsorbed on various catalysts. The red dashed lines represent values corresponding to the free $\mathrm{CO}_{2}$ molecule in Figure 1 (b), (c) and (d). 


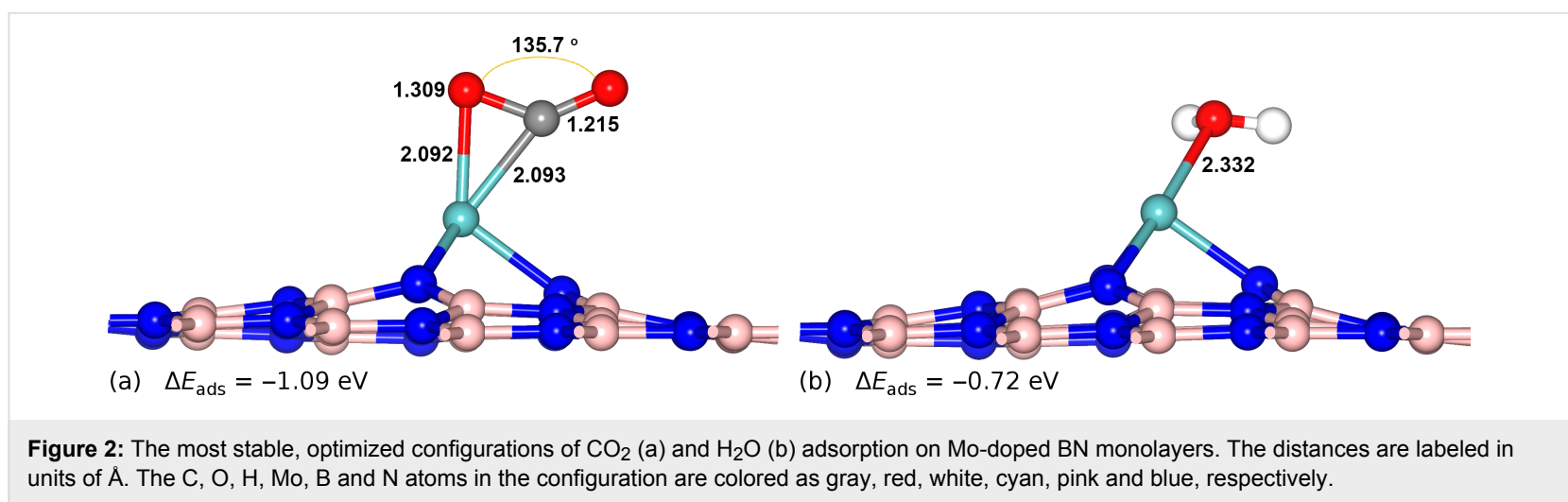

Table S3). The obvious distortions in the geometric configuration are in agreement with the strong chemisorption with an adsorption energy of $-1.09 \mathrm{eV}$, which means that the $\mathrm{CO}_{2}$ is activated by the Mo-doped BN monolayer. The strong adsorption is also supported by a large value $\left(0.482 \mathrm{e}^{-}\right)$of electron transfer from the catalyst to the $\mathrm{CO}_{2}$ molecule. However, for the interaction of $\mathrm{H}_{2} \mathrm{O}$ on the Mo-doped $\mathrm{BN}$ monolayer, the changes in the geometric structure of the $\mathrm{H}_{2} \mathrm{O}$ molecule are different from the adsorbed $\mathrm{CO}_{2}$ (Figure $2 \mathrm{~b}$ and Supporting Information File 1, Table S4) and the adsorption energy of $\mathrm{H}_{2} \mathrm{O}$ on the surface of the catalyst is $-0.72 \mathrm{eV}$. This demonstrates that $\mathrm{CO}_{2}$ not only strongly interacts with and is activated on the Mo-doped $\mathrm{BN}$ monolayer but is also preferable to $\mathrm{H}_{2} \mathrm{O}$. As the projected density of states (Supporting Information File 1, Figure S3) shows, we note that there is an overlapping of the pand d-orbitals of the $\mathrm{CO}_{2}$ absorbed structure located at around $-1.36 /-0.46 \mathrm{eV}$. This is the result of the strong interaction between $\mathrm{CO}_{2}$ and Mo-doped $\mathrm{BN}$ monolayer. For the $\mathrm{H}_{2} \mathrm{O}$ adsorbed on the catalyst, the change in the electronic structure is less obvious than for $\mathrm{CO}_{2}$. This is in good agreement with the observed interaction between $\mathrm{CO}_{2}$ and the Mo-doped $\mathrm{BN}$ monolayer, which is stronger than that of $\mathrm{H}_{2} \mathrm{O}$ with the catalyst. Therefore, the Mo-doped BN monolayer was chosen as the $\mathrm{SAC}$ for the further investigation.

\section{$\mathrm{CO}_{2}$ electrocatalytic reduction}

The reaction mechanism of Mo-doped BN monolayer as a SAC for CRR was investigated via DFT calculations. The profile of the Gibbs free energy of the possible intermediates at each hydrogenation step is shown in Figure 3 and the free energy variations of the main intermediates are displayed in the flow chart at the bottom. The detailed data of Figure 3 are given in Supporting Information File 1, Table S5. We have considered all possible intermediates and the optimized structures of the main product with the lowest energy in each step along the CRR pathways shown in Figure 4. The configurations of the by products are displayed in Supporting Information File 1, Figure S1. As shown in Figure 3, the total Gibbs free energy of the isolated $\mathrm{CO}_{2}$ molecule and the Mo-doped $\mathrm{BN}$ monolayer is defined as zero. For the first step of $\mathrm{CO}_{2}$ hydrogenation, the possible intermediates involve $* \mathrm{OCHO}$ and $* \mathrm{COOH}$. According to the calculated results, the reduction of $\mathrm{CO}_{2}$ to $* \mathrm{OCHO}$ $(\Delta G=-1.35 \mathrm{eV})$ is exothermic with a value of $0.52 \mathrm{eV}$, while the formation of $* \mathrm{COOH}(\Delta G=-0.52 \mathrm{eV})$ is an endothermic reaction of about $0.31 \mathrm{eV}$. These results imply that the early hydrogenation steps may take place at the $\mathrm{C}$ atom of the captured $\mathrm{CO}_{2}$ rather than at the terminal $\mathrm{O}$ atom. The following step involves three competitive intermediates, including ${ }^{*} \mathrm{OCH}_{2} \mathrm{O},{ }^{*} \mathrm{HCOOH}$ and $\mathrm{CH}_{2} \mathrm{O}$ where the ${ }^{*} \mathrm{O}$ atom interacts with the surface of the SACs. Obviously, illustrated in as Figure 4, the evolution of $* \mathrm{OCH}_{2} \mathrm{O}(\Delta G=-1.64 \mathrm{eV})$ in the second step is accompanied by an energy release of $0.29 \mathrm{eV}$. The production of $\mathrm{CH}_{2} \mathrm{O}$ from the surface of the catalyst $(\Delta G=$ $-0.79 \mathrm{eV}$ ) demands an energy input of $0.56 \mathrm{eV}$. The energy input for ${ }^{*} \mathrm{HCOOH}$ is even higher than that of $\mathrm{C}_{2} \mathrm{HO}$, whose value is $0.72 \mathrm{eV}$. Therefore the formation of $* \mathrm{OCH}_{2} \mathrm{O}$ dominates in the second step. The products of the first two steps are agreement with the hypothesis above that the $\mathrm{C}$ atom (rather than the $\mathrm{O}$ atom) is a proton accepting site at the initial reduction reaction stage of the system. Then the third $\mathrm{H}^{+} / \mathrm{e}^{-}$interacts with one of the $\mathrm{O}$ atoms that bonds with Mo atom and products * $\mathrm{HOCH}_{2} \mathrm{O}(\Delta G=-2.17 \mathrm{eV})$. The reaction is exothermic with a value of $0.53 \mathrm{eV}$. The fourth $\mathrm{H}^{+} / \mathrm{e}^{-}$results from the same $\mathrm{O}$ atom of the third step, converting into a $* \mathrm{CH}_{2} \mathrm{O}$ molecule $(\Delta G=-1.89 \mathrm{eV})$ with dissociation of a $\mathrm{H}_{2} \mathrm{O}$ molecule whose reaction is endothermic with a value of $0.28 \mathrm{eV}$. The competitive product is $* \mathrm{HOCH}_{2} \mathrm{OH}(\Delta G=-0.68 \mathrm{eV})$, where $\mathrm{H}^{+} / \mathrm{e}^{-}$bonds with the $\mathrm{O}$ atom at the other side, and the energy input $(1.49 \mathrm{eV})$ is too high to reach. The fifth step, the formation of $* \mathrm{CH}_{3} \mathrm{O}(\Delta G=-2.20 \mathrm{eV})$, is exothermic with a value of $0.31 \mathrm{eV}$. By contrast, the production of $* \mathrm{CH}_{2} \mathrm{OH}$ is an endothermic reaction, which demands $0.84 \mathrm{eV}$ energy input. The sixth $\mathrm{H}^{+} / \mathrm{e}^{-}$is obtained by the ${ }^{*} \mathrm{CH}_{3} \mathrm{O}$, forming $\mathrm{CH}_{3} \mathrm{OH}$ $(\Delta G=-1.42 \mathrm{eV})$ or $\mathrm{CH}_{4}(\Delta G=-2.64 \mathrm{eV})$ which are desorbed from the catalyst. The feasible reaction mechanism of this step is the production of $\mathrm{CH}_{4}$ with an energy release of $0.44 \mathrm{eV}$, 


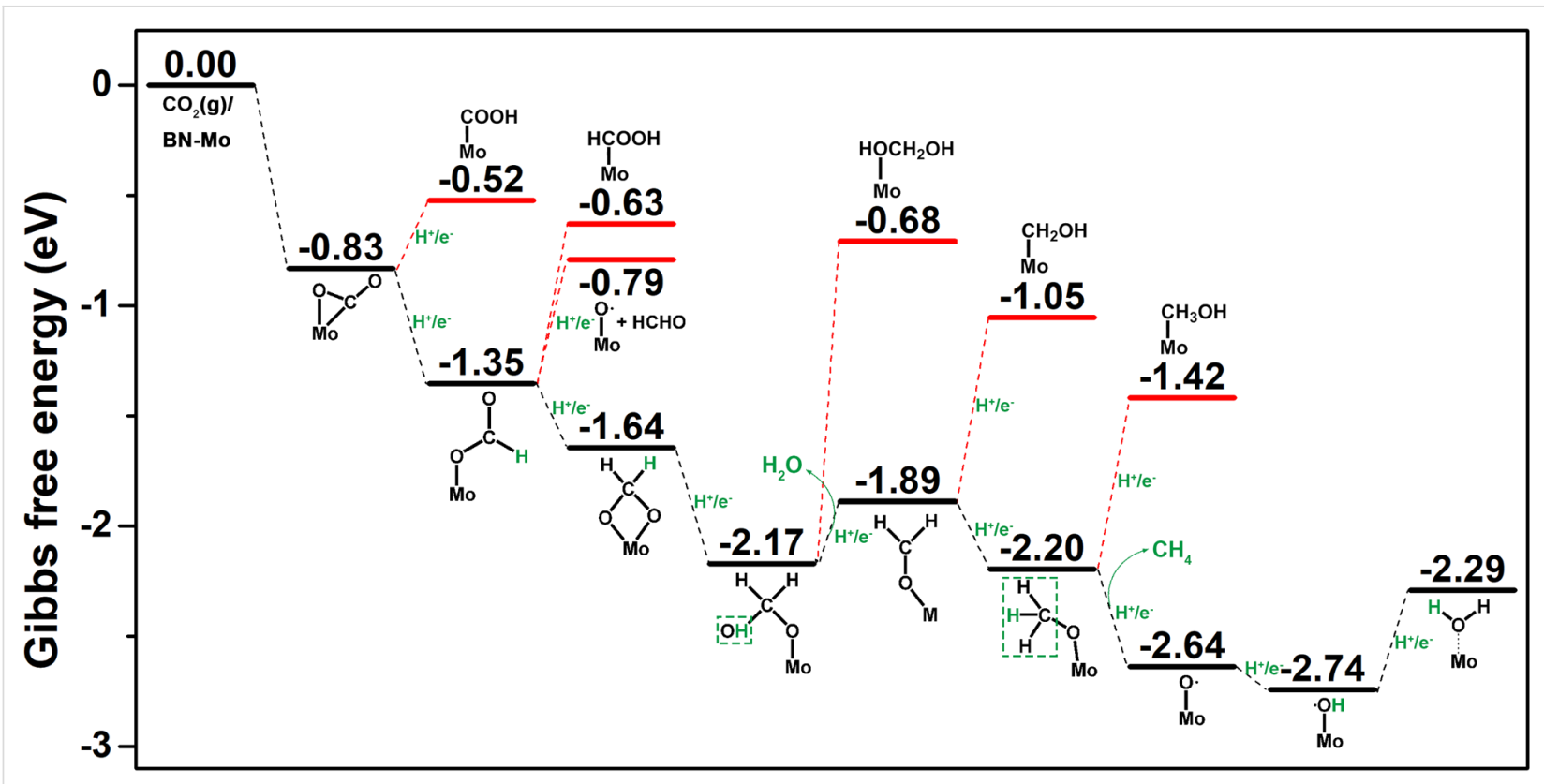

\section{Reaction Pathway}

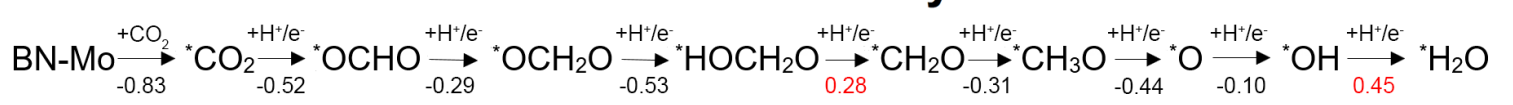

Figure 3: The profile of the Gibbs free energy. A standardized isolated $\mathrm{CO}_{2}$ molecule and a clean Mo-doped $\mathrm{BN}$ monolayer are taken as zero, the minimum free energy pathway for $\mathrm{CO}_{2}$ conversion into $\mathrm{CH}_{4}$ and $\mathrm{H}_{2} \mathrm{O}$ on a Mo-doped BN monolayer. The values of the formation energy intermediates are labelled in units of eV (top). At the bottom, the reaction energies are given in black and the red numbers indicate spontaneous and nonspontaneous reactions in $\mathrm{eV}$, respectively. The asterisk $\left({ }^{*}\right)$ represents intermediates chemisorbed on the Mo-doped BN monolayer.
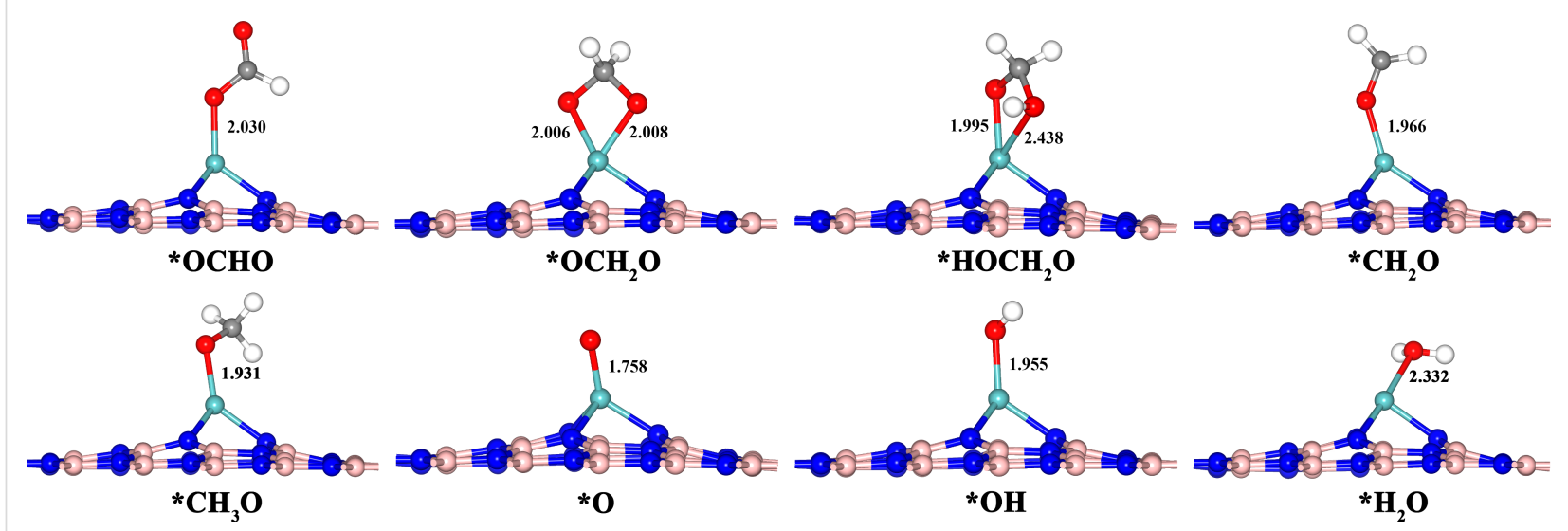

Figure 4: Optimized geometric configurations of the various intermediates with the lowest energy in each step along the reaction pathway of CRR on a Mo-doped BN monolayer. The selected distances are labelled in units of $\AA$. The $\mathrm{C}, \mathrm{O}, \mathrm{H}, \mathrm{Mo}, \mathrm{B}$ and $\mathrm{N}$ atoms in the configuration are colored as gray, red, white, cyan, pink and blue, respectively. The asterisk $\left(^{*}\right)$ represents the chemisorbed species.

while the formation process of $\mathrm{CH}_{3} \mathrm{OH}$ requires an energy input of $0.78 \mathrm{eV}$. As $\mathrm{CH}_{4}$ has formed and desorbed from the surface, there is only a single $\mathrm{O}$ atom to bond with the Mo atom. Therefore, the successive hydrogenation reaction steps are the $\mathrm{H}^{+} / \mathrm{e}^{-}$ interaction with the $\mathrm{O}$ atom to form $* \mathrm{OH}(\Delta G=-2.74 \mathrm{eV})$ and ${ }^{*} \mathrm{H}_{2} \mathrm{O}(\Delta G=-2.29 \mathrm{eV})$. The seventh reaction step, the formation of $* \mathrm{OH}$, occurs with an energy release of $0.10 \mathrm{eV}$, while the energy input for the last step of $\mathrm{H}^{+} / \mathrm{e}^{-}$interacts with $* \mathrm{OH}$ to form $\mathrm{H}_{2} \mathrm{O}$ occurs at a relatively high value of $0.45 \mathrm{eV}$.

From the above analysis, we can explicitly determine that the Mo-doped BN monolayer exhibits high activation and selectivity as an electrocatalyst for $\mathrm{CO}_{2}$ reduction to $\mathrm{CH}_{4}$ along the whole reaction pathway. Moreover, the value of the energy 
input is also noteworthy. To sum up, the rate-determining step of CRR is the last hydrogenation step, ${ }^{*} \mathrm{H}_{2} \mathrm{O}$ production with an energy input $0.45 \mathrm{eV}$ for $\mathrm{CO}_{2}$ reduction to $\mathrm{CH}_{4}$. According to the computational hydrogen electrode (CHE) model, the limiting potential $\left(U_{\text {lim }}\right)$ is defined as: $U_{\text {lim }}=-\Delta G_{\max } / e$, where $\Delta G_{\text {max }}$ is the largest free energy in CRR. Therefore, the limiting potential of CRR on the surface of the Mo-doped BN monolayer is $-0.45 \mathrm{~V}$. A less negative value corresponds to a lower energy input. Moreover, the Gibbs free energy diagram of the HER on the surface of the Mo-doped BN monolayer is shown in Figure S2 in Supporting Information File 1. We clearly see that the limiting potential of CRR and HER on the Mo-doped $\mathrm{BN}$ is $-0.45 \mathrm{~V}$ and $-0.62 \mathrm{~V}$, respectively. Therefore, we can draw the conclusion that the CRR is predominant on the catalyst due to its relatively low energy demand. The limiting potential is relatively low among most of the catalysts to selectively produce $\mathrm{CH}_{4}$ for $\mathrm{CRR}$ with the potential in the range of -0.3 to $-1.0 \mathrm{~V}$, involving noble metal and non-noble metals, both theoretically and experimentally. According to previous research, the application of non-noble metals as catalysts for $\mathrm{CO}_{2}$ reduction to $\mathrm{CH}_{4}$ could overcome the high cost of noble metal catalysts, however, the energy demand is relatively high. For instance, transition-metal carbides have been extensively researched. The energy cost of $\mathrm{CRR}$ on the surface of $\mathrm{Mo}_{2} \mathrm{C}$ [10] and $\mathrm{WC}$ [50] is 0.56 and $1.00 \mathrm{eV}$, respectively. Similarly, Sun et al. reported that the energy input of $\mathrm{Cr}_{3} \mathrm{C}_{2}$ and $\mathrm{Mo}_{3} \mathrm{C}_{2}$ catalyzed in the conversion of $\mathrm{CO}_{2}$ to $\mathrm{CH}_{4}$ is 0.64 and $0.77 \mathrm{eV}$ [9]. In addition, the performance of Mo-doped $\mathrm{BN}$ is comparable to or even better than some catalysts composed of noble metals, such as titania-modified silver $(0.47 \mathrm{eV})$ [48], and osmium and ruthenium atom doped graphene $(0.52 \mathrm{eV})$ [26]. The Mo-doped BN monolayer presents even better performance for selective $\mathrm{CO}_{2}$ reduction than these catalysts. A1though iridium-doped $\mathrm{TiC}$ applied as an electrocatalyst to selec- tively convert $\mathrm{CO}_{2}$ to $\mathrm{CH}_{4}$ is among the best values reported in the literature (limiting potential of $-0.09 \mathrm{~V}$ [51]), iridium as a noble metal that comes at a high cost and has limits to its practical application. Above all, molybdenum as a non-noble-metal doped on $\mathrm{BN}$ monolayers presents both great performance in this theoretical study and is practically feasible for future experimental research.

Although the energy input for the last step is possibly somewhat high, it could be reduced by increasing the coverage of *OH based on the previous study [48]. Once $\mathrm{H}_{2} \mathrm{O}$ has been produced, $\mathrm{CO}_{2}$ can take its position, because $\mathrm{CO}_{2}$ adsorbed on Mo-doped $\mathrm{BN}$ monolayer is more thermodynamically stable than $\mathrm{H}_{2} \mathrm{O}$, as mentioned in Figure 2. In summary, these results mean that the SAC, Mo-doped BN monolayer, can be reused for CRR. In addition, previous investigation has demonstrated that the interaction between Mo and the BN monolayer is very strong, and the catalyst has an excellent thermal stability for long-term use [45]. Overall, the study indicates that the Mo-doped BN monolayer has great potential for use as an efficient SAC for CRR.

\section{CRR mechanisms of the Mo-doped BN monolayer}

To further insight the catalytic performance of the Mo-doped $\mathrm{BN}$ monolayer for the selective CRR, we carried out the charge variation along the reaction pathway by Mulliken charge analysis. According to previous studies [45,52,53], especially the study of Mo-doped BN nanosheets as a catalyst for $\mathrm{N}_{2}$ fixation [45], the intermediate was divided into three moieties for research. These were the $\mathrm{C}_{x} \mathrm{H}_{y} \mathrm{O}_{z}$ (moiety 1) as the product of $\mathrm{CO}_{2}$ hydrogenation reaction of each step, $\mathrm{MoN}_{3}$ (moiety 2) is the Mo atom and the three $\mathrm{N}$ atoms that the Mo atom linked with, and BN monolayer (moiety 3), as shown in Figure 5a. The
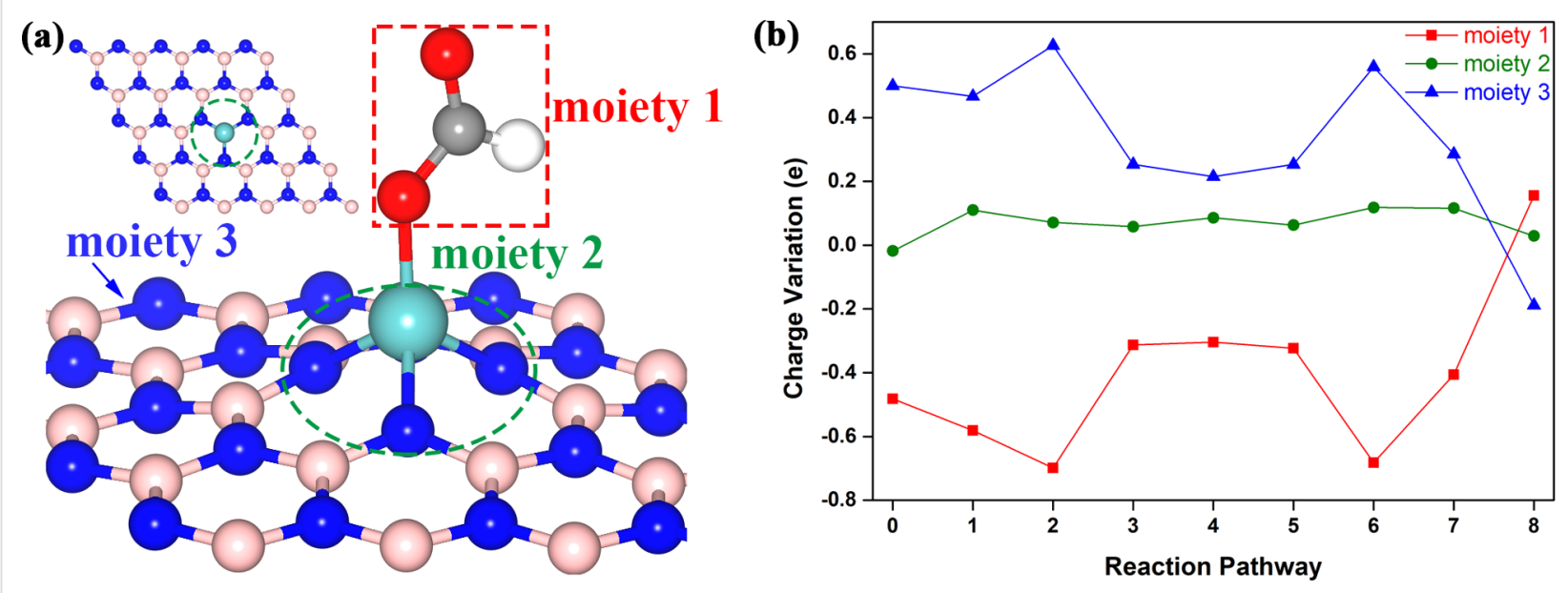

Figure 5: (a) Top and side view of three moieties divided with *OCHO. (b) Charge variation of the three moieties along the reaction pathway. 
variation of the charge distribution is illustrated in Figure $5 \mathrm{~b}$. The step 0 is the charge transfer to the adsorbed $\mathrm{CO}_{2}$. The $\mathrm{CO}_{2}$ molecule and the $\mathrm{MoN}_{3}$ gain 0.482 and 0.018 electrons from the $\mathrm{BN}$ monolayer, respectively. We can see from Figure $5 \mathrm{~b}$ that the charge distributions of moiety 1 and moiety 3 obviously fluctuate with the following hydrogenation reduction steps. For instance, at the step 1 , the moiety 1 (*OCHO) gains 0.581 electrons from both $\mathrm{MoN}_{3}$ and $\mathrm{BN}$ monolayers. In addition, there are about 0.467 electrons from the $\mathrm{BN}$ monolayer which contributes a large part to the total electron. In the same way, the BN monolayer contributes 0.626 electrons which occupy the vast majority of the electrons that moiety $1\left({ }^{*} \mathrm{OCH}_{2} \mathrm{O}\right)$ gained at step 2. Along the whole reaction pathway, the role of the $\mathrm{BN}$ monolayer is to serve as an electron reservoir used for contributing or accepting electrons, while the charge fluctuation of $\mathrm{MoN}_{3}$ is smaller over the whole reaction as compared with previous reports [45,52]. In all, the $\mathrm{MoN}_{3}$ is the active site and can also be defined as a transmitter for charge transfer between the $\mathrm{BN}$ monolayer and moiety 1 .

\section{Conclusion}

In conclusion, we have systematically investigated TM atoms, including $\mathrm{Sc}$ to $\mathrm{Zn}, \mathrm{Mo}, \mathrm{Ru}, \mathrm{Rh}, \mathrm{Pd}$ and $\mathrm{Ag}$, anchored on the boron-defective $\mathrm{BN}$ monolayer as an efficient SAC for CRR, as investigated by means of DFT calculations. The calculated results indicate that the Mo-doped BN monolayer exhibits remarkable electrocatalytic performance for the conversion of $\mathrm{CO}_{2}$ into hydrocarbon fuel. The limiting potential of the $\mathrm{CO}_{2}$ conversion to $\mathrm{CH}_{4}$ on the $\mathrm{SAC}$, Mo-doped $\mathrm{BN}$ monolayer is relatively low with a value of $-0.45 \mathrm{~V}$, which is lower than most non-noble metal catalysts to selectively produce $\mathrm{CH}_{4}$. Therefore, the study demonstrates a potential electrocatalyst employing a non-noble metal with high catalytic efficiency for conversion $\mathrm{CO}_{2}$ into useful fuel under ambient conditions. This work provides important information at the atomic level for experimental researchers in search of low cost and efficient SACs for $\mathrm{CO}_{2}$ reduction.

\section{Computational Methods}

All of the calculations were carried out by means of spin-polarized DFT with the DMol3 code [54,55]. The exchange and correlation potentials were calculated using the Perdew, Burke, and Ernzerhof (PBE) [56] functional within the generalized gradient approximation (GGA) [57]. The van der Waals (vdW) interactions were described using the empirical correction in Grimme's scheme [58]. The calculational method has been successfully used for the investigation of selective adsorption and reaction of gases on BN nanomaterials $[35,45,47]$. The transition metal atoms were produced by density functional semi-core pseudopotential (DSPP), and the valence electronic structure is shown in Supporting Information File 1, Table S7, in which the core electrons are replaced by a single effective potential and the core is treated accurately by introducing some relativistic corrections [59]. The double-numeric polarized (DNP) basis was chosen as the basis set for other elements, which was set with a real-space cutoff at $5.0 \AA$. We used a conductor-like screening model (COSMO) to simulate a water solvent environment [60], and the dielectric constant was 78.54.

To construct the modes, we first built a periodic $5 \times 5 \mathrm{BN}$ supercell, whose vacuum region was $15 \AA$ along the $z$-direction. The single TM atoms were doped at the boron vacancy sites [45]. All of the structures were completely optimized in a unit cell of $12.58 \times 12.58 \times 15.00 \AA^{3}$ with convergence criterion of $1 \times 10^{-6}$ a.u. for the energy and $0.005 \AA$ for the displacements. For the $5 \times 5$ supercell, the k-point sampling of the Brillouin zone (BZ) adopted a $5 \times 5 \times 1$ Monkhorst-Pack grid [61]. The Mulliken charge analysis was employed to calculate the charge distribution and transfer [62].

The whole reaction of $\mathrm{CO}_{2}$ reduction into hydrocarbon products involved eight elementary coupled proton and electron transfer (CPET) steps on the Mo-doped BN monolayer as follows:

$$
\mathrm{CO}_{2}+8 \mathrm{H}^{+}+8 \mathrm{e}^{-} \rightarrow \mathrm{CH}_{4}+2 \mathrm{H}_{2} \mathrm{O}
$$

According to previous studies, a single metal atom performs as the active site for adsorption of gas and formation of carbon reduction intermediates. The hydrogen serves as the proton source $\left(\mathrm{H}_{2} \leftrightarrow 2\left(\mathrm{H}^{+}+\mathrm{e}^{-}\right)\right)$in the $\mathrm{CO}_{2}$ hydrogen evolution reaction of each CPET step $[30,63]$. The Gibbs free energy change $(\Delta G)$ is the relative energy of the total Gibbs free energy of the isolated $\mathrm{CO}_{2}$ molecule and the clean surface of the Mo-doped $\mathrm{BN}$ monolayer, which indicates the thermodynamic feasibly, and is determined as follows:

$$
\Delta G=\Delta E+\Delta Z P E-T \Delta S+\Delta G_{U}+\Delta G_{\mathrm{pH}}
$$

In this equation, $\Delta E$ represents the variation of the reaction energy obtained from DFT calculations as the expression: $\Delta E=E_{\mathrm{AB}}-E_{\mathrm{A}}-E_{\mathrm{B}}$, where $\triangle Z P E$ is zero-point energy (ZPE) difference between the products and reactants in the reaction whose expression is similar to $\Delta E$, where $T$ represents the temperature $(T=298.15 \mathrm{~K})$, and $\Delta S$ represents the change of entropy. The entropies of free gas molecules and vibrational frequencies were all obtained from the NIST database [64], and the data of ZPE and entropy for the gas molecules at $298.15 \mathrm{~K}$ are shown in Table $\mathrm{S} 1$ in the Supporting Information File 1. $\Delta G_{U}$ is the free energy of the electrode potential, which is $\Delta G_{U}=-n_{e} U$ ( $n$ is the number of electrons transferred corresponding to the elementary steps and $U$ is the electrode poten- 
tial). $\Delta G_{\mathrm{pH}}$ is the free energy contribution of the $\mathrm{H}^{+}$concentration. The expression is $\Delta G_{\mathrm{pH}}=2.303 \times k_{\mathrm{B}} T \times \mathrm{pH}$, where $k_{\mathrm{B}}$ is the Boltzmann constant $\left(k_{\mathrm{B}}=1.38 \times 10^{-23} \mathrm{~J} / \mathrm{K}\right)$, and the $\mathrm{pH}$ was set at zero in the study to simulate acidic conditions.

\section{Supporting Information}

\section{Supporting Information File 1}

A detailed description of the dataset.

[https://www.beilstein-journals.org/bjnano/content/

supplementary/2190-4286-10-55-S1.pdf]

\section{Acknowledgements}

Q. Sun acknowledges the support from the National Natural Science Foundation of China (Grant No. 21773164). We also acknowledge the support from A Project Funded by the Priority Academic Program Development of Jiangsu Higher Education Institutions (PAPD).

\section{ORCID ${ }^{\circledR}$ iDs}

Qiao Sun - https://orcid.org/0000-0002-8770-7847

\section{References}

1. Karl, T. R.; Trenberth, K. E. Science 2003, 302, 1719-1723. doi:10.1126/science.1090228

2. Hoffert, M. I.; Caldeira, K.; Benford, G.; Criswell, D. R.; Green, C.; Herzog, H.; Jain, A. K.; Kheshgi, H. S.; Lackner, K. S.; Lewis, J. S.; Lightfoot, H. D.; Manheimer, W.; Mankins, J. C.; Mauel, M. E.; Perkins, L. J.; Schlesinger, M. E.; Volk, T.; Wigley, T. M. L. Science 2002, 298, 981-987. doi:10.1126/science.1072357

3. D'Alessandro, D. M.; Smit, B.; Long, J. R. Angew. Chem., Int. Ed. 2010, 49, 6058-6082. doi:10.1002/anie.201000431

4. Pires, J. C. M.; Martins, F. G.; Alvim-Ferraz, M. C. M.; Simoes, M. Chem. Eng. Res. Des. 2011, 89, 1446. doi:10.1016/j.cherd.2011.01.028

5. Sun, Q.; Qin, G.; Ma, Y.; Wang, W.; Li, P.; Du, A.; Li, Z. Nanoscale 2017, 9, 19-24. doi:10.1039/c6nr07001a

6. Whipple, D. T.; Kenis, P. J. A. J. Phys. Chem. Lett. 2010, 1, 3451-3458. doi:10.1021/jz1012627

7. Kondratenko, E. V.; Mul, G.; Baltrusaitis, J.; Larrazábal, G. O.; Pérez-Ramírez, J. Energy Environ. Sci. 2013, 6, 3112. doi:10.1039/c3ee41272e

8. Liu, C.; Yang, B.; Tyo, E.; Seifert, S.; DeBartolo, J.; von Issendorff, B.; Zapol, P.; Vajda, S.; Curtiss, L. A. J. Am. Chem. Soc. 2015, 137, 8676-8679. doi:10.1021/jacs.5b03668

9. Li, N.; Chen, X.; Ong, W.-J.; MacFarlane, D. R.; Zhao, X.; Cheetham, A. K.; Sun, C. ACS Nano 2017, 11, 10825-10833. doi:10.1021/acsnano.7b03738

10. Kim, S. K.; Zhang, Y.-J.; Bergstrom, H.; Michalsky, R.; Peterson, A. ACS Catal. 2016, 6, 2003-2013. doi:10.1021/acscatal.5b02424

11. Hu, G.; Wu, Z.; Dai, S.; Jiang, D.-E. ACS Appl. Mater. Interfaces 2018, 10, 6694-6700. doi:10.1021/acsami.7b17600

12. Costentin, C.; Robert, M.; Savéant, J.-M. Chem. Soc. Rev. 2013, 42, 2423-2436. doi:10.1039/c2cs35360a
13. Agarwal, A. S.; Zhai, Y.; Hill, D.; Sridhar, N. ChemSusChem 2011, 4 , 1301-1310. doi:10.1002/cssc.201100220

14. Lu, Q.; Rosen, J.; Zhou, Y.; Hutchings, G. S.; Kimmel, Y. C.; Chen, J. G.; Jiao, F. Nat. Commun. 2014, 5, 3242. doi:10.1038/ncomms4242

15. Yan, H.; Cheng, H.; Yi, H.; Lin, Y.; Yao, T.; Wang, C.; Li, J.; Wei, S.; Lu, J. J. Am. Chem. Soc. 2015, 137, 10484-10487. doi:10.1021/jacs.5b06485

16. Xie, L.; Brault, P.; Coutanceau, C.; Bauchire, J.-M.; Caillard, A.; Baranton, S.; Berndt, J.; Neyts, E. C. Appl. Catal., B 2015, 162, 21-26. doi:10.1016/j.apcatb.2014.06.032

17. Tyo, E. C.; Vajda, S. Nat. Nanotechnol. 2015, 10, 577-588. doi:10.1038/nnano.2015.140

18. Kaden, W. E.; Wu, T.; Kunkel, W. A.; Anderson, S. L. Science 2009, 326, 826-829. doi:10.1126/science.1180297

19. Yudanov, I. V.; Genest, A.; Schauermann, S.; Freund, H.-J.; Rösch, N. Nano Lett. 2012, 12, 2134-2139. doi:10.1021/nl300515z

20. Crespo-Quesada, M.; Yarulin, A.; Jin, M.; Xia, Y.; Kiwi-Minsker, L. J. Am. Chem. Soc. 2011, 133, 12787-12794. doi:10.1021/ja204557m

21. Ling, C.; Shi, L.; Ouyang, Y.; Zeng, X. C.; Wang, J. Nano Lett. 2017, 17, 5133-5139. doi:10.1021/acs.nanolett.7b02518

22. Qiao, B.; Wang, A.; Yang, X.; Allard, L. F.; Jiang, Z.; Cui, Y.; Liu, J.; Li, J.; Zhang, T. Nat. Chem. 2011, 3, 634-641. doi:10.1038/nchem.1095

23. Yang, X.-F.; Wang, A.; Qiao, B.; Li, J.; Liu, J.; Zhang, T. Acc. Chem. Res. 2013, 46, 1740-1748. doi:10.1021/ar300361m

24. Zhang, B.; Asakura, H.; Zhang, J.; Zhang, J.; De, S.; Yan, N. Angew. Chem., Int. Ed. 2016, 55, 8319-8323. doi:10.1002/anie.201602801

25. Zhang, W.; Zheng, W. Adv. Funct. Mater. 2016, 26, 2988-2993. doi:10.1002/adfm.201600240

26. Back, S.; Lim, J.; Kim, N.-Y.; Kim, Y.-H.; Jung, Y. Chem. Sci. 2017, 8, 1090-1096. doi:10.1039/c6sc03911a

27. Liu, S.; Huang, S. Carbon 2017, 115, 11-17. doi:10.1016/j.carbon.2016.12.094

28. Zhang, X.; Guo, J.; Guan, P.; Liu, C.; Huang, H.; Xue, F.; Dong, X.; Pennycook, S. J.; Chisholm, M. F. Nat. Commun. 2013, 4, 1924. doi:10.1038/ncomms2929

29. Wang, Z.; Zhao, J.; Cai, Q. Phys. Chem. Chem. Phys. 2017, 19, 23113-23121. doi:10.1039/c7cp04299j

30. Gao, G.; Jiao, Y.; Waclawik, E. R.; Du, A. J. Am. Chem. Soc. 2016, 138, 6292-6297. doi:10.1021/jacs.6b02692

31. He, F.; Li, K.; Yin, C.; Wang, Y.; Tang, H.; Wu, Z. Carbon 2017, 114, 619-627. doi:10.1016/j.carbon.2016.12.061

32. Li, X.; Cui, P.; Zhong, W.; Li, J.; Wang, X.; Wang, Z.; Jiang, J. Chem. Commun. 2016, 52, 13233-13236. doi:10.1039/c6cc07049c

33. Li, X.; Bi, W.; Zhang, L.; Tao, S.; Chu, W.; Zhang, Q.; Luo, Y.; Wu, C.; Xie, Y. Adv. Mater. (Weinheim, Ger.) 2016, 28, 2427-2431. doi:10.1002/adma.201505281

34. Zhao, J.; Zhao, J.; Li, F.; Chen, Z. J. Phys. Chem. C 2018, 122, 19712-19721. doi:10.1021/acs.jpcc.8b06494

35. Sun, Q.; Li, Z.; Searles, D. J.; Chen, Y.; Lu, G.; Du, A. J. Am. Chem. Soc. 2013, 135, 8246-8253. doi:10.1021/ja400243r

36. Weng, Q.; Wang, X.; Wang, X.; Bando, Y.; Golberg, D. Chem. Soc. Rev. 2016, 45, 3989-4012. doi:10.1039/c5cs00869g

37. Pang, J.; Chao, Y.; Chang, H.; Li, H.; Xiong, J.; Zhang, Q.; Chen, G.; Qian, J.; Zhu, W.; Li, H. ACS Sustainable Chem. Eng. 2018, 6, 4948-4957. doi:10.1021/acssuschemeng.7b04481

38. Watanabe, K.; Taniguchi, T.; Kanda, H. Nat. Mater. 2004, 3, 404-409. doi:10.1038/nmat1134 
39. Choi, H.; Park, Y. C.; Kim, Y.-H.; Lee, Y. S. J. Am. Chem. Soc. 2011, 133, 2084-2087. doi:10.1021/ja1101807

40. Watanabe, K.; Taniguchi, T.; Niiyama, T.; Miya, K.; Taniguchi, M. Nat. Photonics 2009, 3, 591-594. doi:10.1038/nphoton.2009.167

41. Golberg, D.; Bando, Y.; Huang, Y.; Terao, T.; Mitome, M.; Tang, C.; Zhi, C. ACS Nano 2010, 4, 2979-2993. doi:10.1021/nn1006495

42. Jin, C.; Lin, F.; Suenaga, K.; lijima, S. Phys. Rev. Lett. 2009, 102, 195505. doi:10.1103/physrevlett.102.195505

43. Sun, W.; Meng, Y.; Fu, Q.; Wang, F.; Wang, G.; Gao, W.; Huang, X.; Lu, F. ACS Appl. Mater. Interfaces 2016, 8, 9881-9888. doi:10.1021/acsami.6b01008

44. Lin, Y.; Connell, J. W. Nanoscale 2012, 4, 6908-6939. doi:10.1039/c2nr32201c

45. Zhao, J.; Chen, Z. J. Am. Chem. Soc. 2017, 139, 12480-12487. doi:10.1021/jacs.7b05213

46. Lin, S.; Ye, X.; Johnson, R. S.; Guo, H. J. Phys. Chem. C 2013, 117, 17319-17326. doi:10.1021/jp4055445

47. Sun, Q.; Sun, C.; Du, A.; Li, Z. J. Phys. Chem. C 2014, 118, 30006-30012. doi:10.1021/jp510387h

48. Zhai, L.; Cui, C.; Zhao, Y.; Zhu, X.; Han, J.; Wang, H.; Ge, Q. J. Phys. Chem. C 2017, 121, 16275-16282. doi:10.1021/acs.jpcc.7b03314

49. Azofra, L. M.; MacFarlane, D. R.; Sun, C. Chem. Commun. 2016, 52, 3548-3551. doi:10.1039/c5cc07942j

50. Wannakao, S.; Artrith, N.; Limtrakul, J.; Kolpak, A. M. ChemSusChem 2015, 8, 2745-2751. doi:10.1002/cssc.201500245

51. Backs, S.; Jung, Y. ACS Energy Lett. 2017, 2, 969-975. doi:10.1021/acsenergylett.7b00152

52. Li, X.-F.; Li, Q.-K.; Cheng, J.; Liu, L.; Yan, Q.; Wu, Y.; Zhang, X.-H.; Wang, Z.-Y.; Qiu, Q.; Luo, Y. J. Am. Chem. Soc. 2016, 138, 8706-8709. doi:10.1021/jacs.6b04778

53. Le, Y.-Q.; Gu, J.; Tian, W. Q. Chem. Commun. 2014, 50, 13319-13322. doi:10.1039/c4cc01950d

54. Delley, B. J. Chem. Phys. 1990, 92, 508-517. doi:10.1063/1.458452

55. Delley, B. J. Chem. Phys. 2000, 113, 7756-7764. doi:10.1063/1.1316015

56. Perdew, J. P.; Ernzerhof, M. J. Chem. Phys. 1996, 105, 9982-9985. doi:10.1063/1.472933

57. Perdew, J. P.; Burke, K.; Ernzerhof, M. Phys. Rev. Lett. 1996, 77, 3865-3868. doi:10.1103/physrevlett.77.3865

58. Grimme, S. J. Comput. Chem. 2006, 27, 1787-1799. doi:10.1002/jcc.20495

59. Delley, B. Phys. Rev. B 2002, 66, 155125. doi:10.1103/physrevb.66.155125

60. Klamt, A.; Schüürmann, G. J. Chem. Soc., Perkin Trans. 2 1993, 799-805. doi:10.1039/p29930000799

61. Monkhorst, H. J.; Pack, J. D. Phys. Rev. B 1976, 13, 5188-5192. doi:10.1103/physrevb.13.5188

62. Mulliken, R. S. J. Chem. Phys. 1955, 23, 1833-1840. doi:10.1063/1.1740588

63. Zheng, Y.; Jiao, Y.; Zhu, Y.; Li, L. H.; Han, Y.; Chen, Y.; Du, A.; Jaroniec, M.; Qiao, S. Z. Nat. Commun. 2014, 5, 3783. doi:10.1038/ncomms4783

64. Computational Chemistry Comparison and Benchmark Database. https://cccbdb.nist.gov/.

\section{License and Terms}

This is an Open Access article under the terms of the Creative Commons Attribution License (http://creativecommons.org/licenses/by/4.0). Please note that the reuse, redistribution and reproduction in particular requires that the authors and source are credited.

The license is subject to the Beilstein Journal of Nanotechnology terms and conditions:

(https://www.beilstein-journals.org/bjnano)

The definitive version of this article is the electronic one which can be found at:

doi:10.3762/bjnano.10.55 